\title{
German librarians cautious of brave new digital world
}

Quirin Schiermeier, Munich

German librarians are quietly concerned by a recommendation that they increase their efforts to provide electronic services. Although supportive in principle, they are wary of being asked to do too much, too quickly.

The call comes from Germany's science council, the Wissenschaftsrat, which has looked at electronic publishing and archiving in its proposals on the future development of the German science system, published last week (see Nature 406, 116;2000).

But librarians warn, for example, that there are as yet no satisfactory solutions for reliable long-term archiving of digital media. They also point out that, contrary to many predictions, the emergence of electronic publications has not led to a decrease in print publications.

One of the council's suggestions - an electronic catalogue of the entire stock of German scientific institutes' printed and electronic resources - is already approaching completion.

The Wissenschaftsrat also says that as many existing library resources as "economically justifiable" should be electronically converted. Scientists in Germany, it argues, should have remote full-text access to as many publications as possible.

But many librarians believe this is overoptimistic. They argue that the systematic digitizing of library stocks would be of little use for most scientists, and unrealistically expensive. Desktop access, they say, should be limited to key journals and frequently used reference books.

"Digitization projects require a lot of time and money," says Uwe Drewen, head of the working group for scientific librarianship at the Deutsche Forschungsgemeinschaft (DFG), Germany's main research funding agency. "They have to be selected with extreme prudence."

Since 1997, the DFG has approved DM21 million for 63 projects aimed at digitizing selected library stocks. It has also helped to set up digitizing centres in Munich and Göttingen which support libraries in converting print material.

As for direct electronic publishing, the

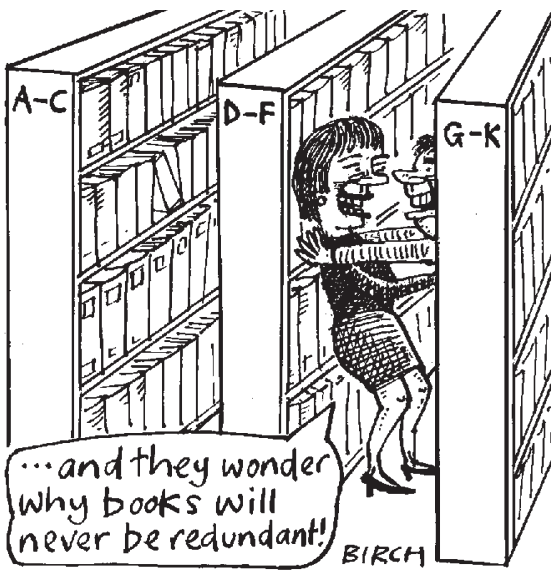

Wissenschaftsrat accepts that there is no satisfactory solution yet for the long-term archiving of digital publications.

According to Volker Henze, head of the archiving department of the Deutsche Bibliothek (DDB), Germany's national library, no technical solution for guaranteeing the accessibility and integrity of files over the coming generations of computer formats, languages and internet platforms has so far proved feasible.

Meanwhile, the rate at which printed versions of books, journals and university proceedings are deposited in the DDB shows no signs of slowing down. 